\title{
Ultrasensitive electrochemical detection of metal ions using dicarboethoxycalixarene- based sensor
}

\begin{abstract}
In this paper, we have reported an electrochemical detection of metal ions based on Calixarene-based sensor. In the sensing strategy, 3-aminopropylsilane (APTMS) was initially self-assembled on indium tin oxide (ITO) followed by functionalization of dicarboethoxycalix [4]arene (EtC4). The morphology and properties of electrodes were characterized by contact angle, atomic force microscopy, cyclic voltammetry, electrochemical impedance spectroscopy and X-ray photoelectron spectroscopy. The electrochemical response characteristics of the modified electrodes (EtC4/APTMS/ITO) towards analyte ions; Zn(II), $\mathrm{Cu}(\mathrm{II})$, and $\mathrm{Fe}(\mathrm{II})$ ions were investigated by differential pulse voltammetry (DPV) under optimized conditions. It was found that the response of modified electrode towards the analytes was improved significantly as compared to the ITO electrode and resulted in limit of detections (LOD) of $9.88 \mathrm{pg} / \mathrm{L}, 8.33 \mu \mathrm{g} / \mathrm{L}$ and $1.15 \mu \mathrm{g} / \mathrm{L}$, respectively. In addition, the detection limit of simultaneous detection quantification of $\mathrm{Cu} 2+, \mathrm{Zn} 2+$ and $\mathrm{Fe} 2+$ ions could be achieved with the concentration $6.19 \mathrm{ng} / \mathrm{L}, 3.02 \mathrm{mg} / \mathrm{L}$ and $2.79 \mathrm{mg} / \mathrm{L}$, respectively. It is worth to show that dicarboethoxy-calix [4] arene modified electrode is a promising candidate as electrochemical sensors for simultaneous and ultrasensitive heavy metal ions determination.
\end{abstract}

Keyword: Calixarene; Heavy metals; Functionalization; Indium tin oxide; Electrochemical sensor; Modified electrode 